\title{
Modelling delay saving through pro-active incident management techniques
}

\author{
Nicholas B. Taylor ${ }^{1}$ (D) $\cdot$ Johan Olstam $^{2,3} \cdot$ Viktor Bernhardsson $^{2} \cdot$ Philippe Nitsche $^{4}$
}

Received: 8 March 2017 / Accepted: 5 September 2017 /Published online: 26 September 2017

(C) The Author(s) 2017. This article is an open access publication

\begin{abstract}
Purpose Road traffic incidents cause delay, affect public safety and the environment. The CEDR PRIMA project aims to extend practical guidance for traffic managers in pro-active Traffic Incident Management (TIM) techniques to reduce the impacts and associated costs of incidents.

Methods The paper describes modelling methods used in the project for assessing the effect of different management techniques on incident duration and travel delay under various scenarios, including collision, adverse weather, heavy vehicle breakdown and other obstruction, assuming various management strategies and generic impacts of novel technologies. Macroscopic simulations of 178 variations of 13 basic scenarios have been performed using a flexible and computationally efficient
\end{abstract}

Nicholas B. Taylor

nicholas.b.taylor@alumni.ucl.ac.uk

Johan Olstam

johan.olstam@vti.se; johan.olstam@liu.se

Viktor Bernhardsson

viktor.bernhardsson@vti.se

Philippe Nitsche

philippe.nitsche@ait.ac.at

1 Transport Research Laboratory (TRL), Crowthorne House, Wokingham RG40 3GA, UK

2 Swedish National Road and Transport Research Institute (VTI), Olaus Magnus väg 35, SE-581 95 Linköping, Sweden

3 Department of Science and Technology, Division for Communication and Transport Systems, Linköping University, SE-601 74 Norrköping, Sweden

4 AIT Austrian Institute of Technology, TECHbase Vienna, Giefinggasse 2, 1210, Vienna, Austria macroscopic queue model, results being verified by simulation using a velocity-based Cell Transmission Model (CTM-v).

Results The results of the two modelling methods are broadly consistent. While delays estimated by the two methods can differ by up to $20 \%$, this is small compared to the factor of 30 range of modelled delays caused by incidents, depending on their nature and circumstances, and is not sufficient to affect general conclusions. Under the peak traffic conditions assumed, the most important factor affecting delay is whether running lanes can be kept open, but quick clearance of carriageway is not always feasible.

Conclusions Comparison of two very different modelling methods confirms their consistency within the context of highly scenario-dependent results, giving confidence in the results. Future research and data needs include further validation of the models, potential application to traffic flow and conflict prediction and incident prevention, and more complete and consistent recording of incident timelines and impacts.

Keywords Traffic incident $\cdot$ Delay $\cdot$ Modelling $\cdot$ Incident management $\cdot$ Novel technology $\cdot$ Intelligent transportation systems

\section{Introduction}

This paper reports the methods and results of modelling road traffic incident scenarios in the project PRo-active Incident MAnagement (PRIMA) [1-3], following on from tasks on Traffic Incident Management (TIM) and Traffic Management in previous phases of research funded by the Conference of European Directors of Roads [4-6].

Unpredictable road traffic incidents cause delays and costs that diminish the overall performance of the road system and can be serious especially where roads are operating close to 
capacity. Traffic Incident Management (TIM), as practice with formal procedures or guidelines, has developed in response to the increase of motorways and expressways equipped with monitoring and control systems managed by traffic management centres (TMC), in the presence of road traffic growth and increased use of these road types by local peak traffic. Incidents are customarily attended by police, and in many countries TIM is led by police even when not managed by them. TMCs generally coordinate several responders including ambulance, fire/rescue, repair and clearance services. Highways England [7] defined the roles and responsibilities of different responders, including TMC, police, fire/rescue, medical and repair/towing services, and set up regular inter-agency meetings and exercises. The Netherlands Rijkswaterstaat (RWS) developed its 'Red/Blue Book' with the same purpose [8]. Statens vegvesen in Norway also developed written guidelines, and Vejdirektoratet in Denmark conducts multi-responder exercises. These and other European national road administrations formed consortia in CEDR Tasks 5 and 13, led by Highways England, to identify current and best practice in TIM, and to develop common guidelines for deployment of TIM in Europe allowing for different levels of development in member states $[4,5,9]$. The purpose of PRIMA is to extend these projects by identifying in general terms 'pro-active' management techniques and facilities which may make TIM more cost-effective.

Predictive or highly automated systems are excluded from PRIMA's remit, although the impact of novel Intelligent Transportation Systems (ITS) such as Advanced eCall is included in a cost-benefit analysis [3]. Conventional ITS can be considered to have an implicit role, as it is assumed that traffic managers have sufficiently detailed real time information to enable them to dispatch prompt incident response. This may take the form of 'Controlled' motorways which first appeared in the 1990s in the form of MIDAS ${ }^{1}$ in the UK, and MTM in the Netherlands and Sweden, where advisory or mandatory speed limits and message signs can be set automatically depending on traffic speed or volume. MIDAS, for example, includes detector loops in each lane at least every $500 \mathrm{~m}$, deployable mandatory speed limits and lane closure signs over each lane, and software that sets speed limits according to traffic volume thresholds, supplemented by $40 \mathrm{mph}(64 \mathrm{~km} /$ h) speed limits commanded by a rapid-acting occupancy detector (HIOCC). Visualisation software, such as Motorgraph (formerly MTV) developed by TRL, enables performance monitoring. Recently, these systems have been extended to 'Smart' motorways able to vary the number of available lanes semi-automatically by opening the hard shoulder or defining narrower lanes. Similar systems are deployed in many countries.

\footnotetext{
${ }^{1}$ Motorway Incident Detection and Automatic Signalling developed by Highways England (then the English Highways Agency) and first installed on the busy south-western quadrant of the M25 London orbital.
}

This paper deals specifically with traffic modelling whose objective is to efficiently estimate queues and delays and compare techniques under a large number of generic scenario assumptions, to obtain a representative set of results. Therefore, the modelling does not deal with specific sites or events, and accounts for novel technology only in terms of its possible broad effect on initial detection and response times, which are assumed short in comparison with scene management time so contribute marginally to delay. The scope of modelling embraces four generic incident scenarios and several scene management techniques including 'quick clearance' of the carriageway. ${ }^{2}$ In order to model a large number of combinations of scenario elements efficiently, a macroscopic ${ }^{3}$ queue model has been developed, implemented in a spreadsheet. This is compared with and verified by a more detailed macroscopic simulation using a velocity-based Cell Transmission Model (CTM-v). Both methods model incidents through several distinct phases and take account of the variation of traffic demand with time. The results indicate agreement within a range of $10-20 \%$, in the context of a factor 30 absolute range of delays.

The rest of the paper is structured as follows: description of methodology, mathematical description of modelling methods, calibration and implementation, analysis and discussion of results, and conclusions including future data and research needs.

\section{Methodology and configuration}

From the viewpoint of traffic modelling, the main impact of an incident is a reduction in traffic capacity, the magnitude of which will depend on the nature of the incident, and the phase of the scene management process. The aim of the traffic modelling approaches adopted is to estimate the queue build up and discharge in different types of incident under different assumptions about management techniques, and the consequent delay to road users, from which potential cost saving is obtainable by applying values of time and taking into account the risk of secondary accidents. Given the inherent variability of traffic and incidents and the delays they cause, it is necessary to model a large number of cases. Modelling therefore has to be efficient enough to evaluate many combinations of scenario, traffic demand level, scene management technique, and possible impact of novel technology. While offering efficient evaluation,

\footnotetext{
${ }^{2}$ Quick clearance generally requires legal sanction because it may compromise accident investigation and court proceedings, but it is legal in some States of the USA and is becoming more widely accepted.

${ }^{3}$ Macroscopic simulation essentially treats traffic as a fluid during specific time periods, as opposed to microscopic simulation which represents motion of vehicles individually.
} 
this may sacrifice some detail and precision. Therefore two very different approaches are used and compared:

1) An aggregate macroscopic queue model, resolving time to periods representing distinct phases of an incident, allowing flexible definition and rapid evaluation of a large number of combinations of incident scenario and management strategy, with allowance in general terms for the impact of new technology on initial response time.

2) A more disaggregate macroscopic traffic simulation using the velocity-based Cell Transmission Method (CTM-v), allowing detailed simulation of the traffic state expressed by flow, speed and density over space and time, and verification of the results of the aggregate queue model.

\subsection{Incident scenarios}

Four basic incident scenarios are considered, representing collision, adverse weather, breakdown of large goods vehicle (LGV), and debris or shed load obstructing the carriageway. The scenarios are further subdivided by management technique as listed in Table 1, and detailed description of the stages of the incident, and length and intensity of traffic peak (see Section 4.3). See also Nitsche et al. [1]. Scene management techniques, applied as appropriate to each scenario, include physical measures like incident screens, physical screens erected between the carriageways to reduce 'rubber-necking' distraction on the opposite carriageway (see Section 4.1), contra-flow to remove traffic from the immediate vicinity of the incident, and 'quick clearance' of the carriageway, as well as management on site. The effect of advance information displayed on a notional Variable Message Sign (VMS) combined with a speed limit is represented in some cases (see Section 4.2).

An incident is assumed to be divided into five phases: Initial, Scene Management, an optional 'Respite' phase possibly lasting several hours, Clearance and Recovery. The Initial phase is subdivided into Discovery, Verification and Initial Response because these can be affected differently depending on the services and technology available. A Respite phase applies where final clearance of the carriageway is delayed until the off-peak to minimise disruption. The road configurations assumed are 3-lane urban motorway with free-flow speed of $80 \mathrm{~km} / \mathrm{h}$ (S1 and S3), and 2-lane inter-urban motorway with free-flow speed of $116 \mathrm{~km}$ (S2 and S4). These choices reflect a focus on urban regions and Swedish rather than British motorways.

The modelled incident scenarios are generic. Their precise details, whether single or multiple vehicle, casualties involved, etc., are not considered, as the concern is the effect of an incident on capacity in relation to demand. Once an incident has occurred, free-flow speed has little effect on results. Where a speed limit is applied (Technique 2.3) this is assumed to be $50 \mathrm{~km} / \mathrm{h}$. The effect of novel technology like Advanced eCall, and its penetration, is represented broadly as Low (essentially absent), Medium or High level, with corresponding reductions in the length of initial response phases, as detailed by Nitsche et al. [1].

\subsection{Modelling traffic demand}

AM peak demand profiles are divided into Low and High peaks applied to the 2-lane inter-urban motorway model, with further division into Short and Long peaks for the 3-lane urban motorway model. In cases where these distinctions are not required, peaks of intermediate height or length are used. Profiles are defined in relative terms with 15-min resolution, factored up appropriately and averaged to obtain the absolute demand profile or the total demand in each incident phase. The maximum flows and approximate durations are illustrated in Fig. 1, bearing in mind that AM peaks tend to rise quickly but their fall is less well defined as they merge into inter-peak traffic. Peak volumes are set so that there should be no queuing under normal conditions.

\section{Modelling of dynamic traffic flow and queuing}

\subsection{Basic model description}

Figure 2 is a schematic illustration of a road section partly obstructed by an incident. After travelling some distance traffic arrives on the upstream road section (a) and meets a queue (b) resulting from reduced capacity through the incident site. In the zone of influence of the incident, the traffic throughput

Table 1 Overview of modelled incident scenarios and techniques

\begin{tabular}{lllll}
\hline Scenario & TIM techniques modelled & & \\
\hline S1: Collision & 1.1 Close all 3 lanes & 1.2 Incident screen & 1.3 Close 2 of 3 lanes & 1.4 Tow in off-peak \\
S2: Weather event & 2.1 Close both 2 lanes & 2.2 Contraflow & 2.3 VMS + Speed limit \\
S3: LGV breakdown & 3.1 Close 1 lane of 3 & 3.2 Repair on-site & 3.3 Tow in off-peak & (closing 2 lanes) \\
S4: Obstruction & 4.1 Close both 2 lanes & 4.2 Contraflow & 4.3 Close blocked lane & \\
\hline
\end{tabular}


Fig. 1 Main demand peak profiles (some intermediate cases are also used)
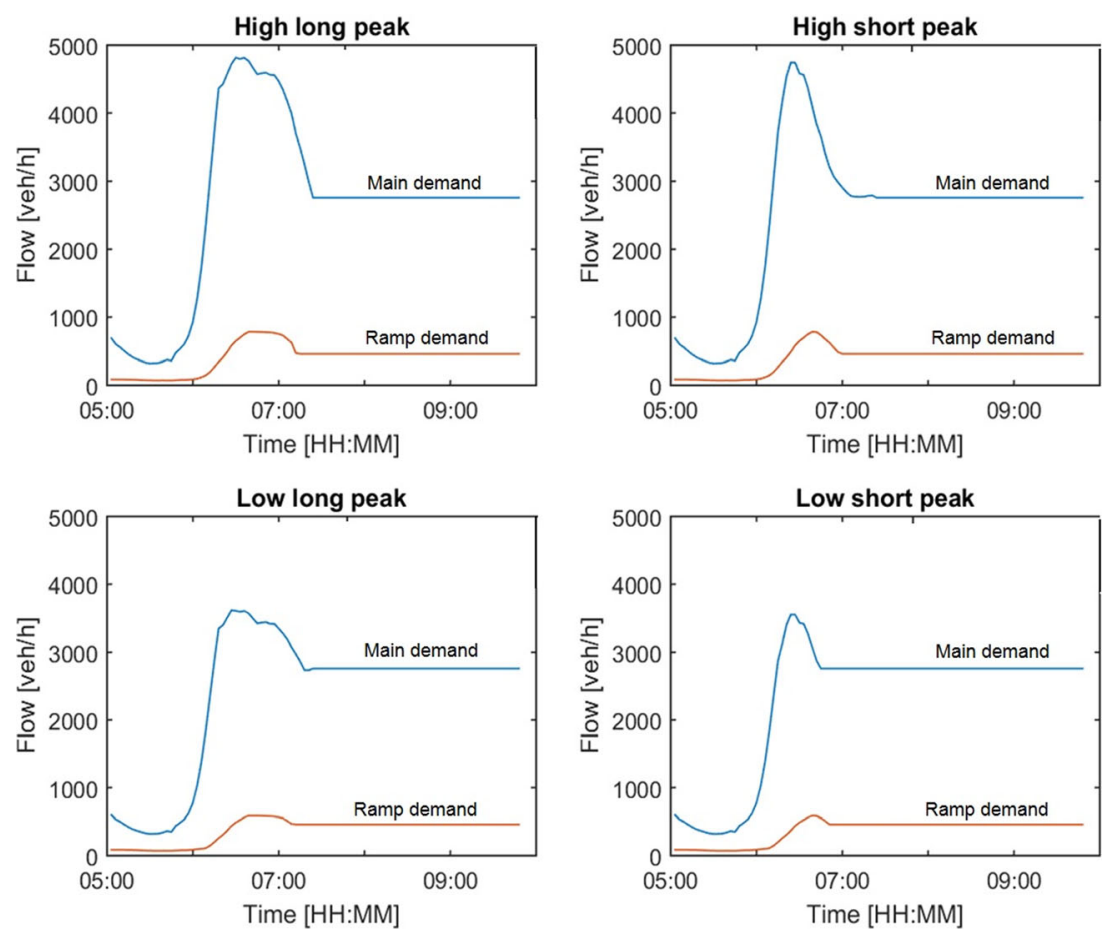

depends on the remaining capacity provided by any lanes that remain open (c), which may have less than their normal capacity because of narrowing, a speed limit or 'lateral discomfort' in the presence of police and other emergency attendance. Downstream of the incident site (d), normal capacity is assumed to be restored and vehicles can accelerate away so the traffic conditions eventually return to normality, although the initial high density of traffic can lead to reduced speed persisting over many kilometres. The main variables used are listed in Table 2.

The traffic state at any point in space and time can be represented by local or instantaneous volume, speed and density, related by the Fundamental Relationship of Traffic:

$q=v \cdot \rho$

Diagrams representing the pairwise relationships between these variables ${ }^{4}$ assumed here are shown in Fig. 3, which treat 'uncongested' and 'congested' regimes separately. Important parameters are maximum free flow speed $\left(V_{f}\right)$, jam density $\left(\rho_{\max }\right)$ where speed and flow are zero, and the critical density $\left(\rho_{c}\right)$ and speed $\left(v_{c}\right)$ where the regimes meet, smooth flow typically breaks down and queuing develops, and the state where maximum flow occurs corresponds to notional capacity $(\mu)$.

\footnotetext{
${ }^{4}$ Sometimes referred to inaccurately as the 'fundamental diagram' by analogy with Eq. (1), as a specific model of traffic behaviour is assumed and none has been definitively established as representing reality.
}

The models adopted here are members of a well-known family of 'stimulus-response' models, see e.g. Taylor et al. [10] for a summary and references. In the uncongested regime a linear speed/flow relationship is assumed. In the congested regime, the characteristic property is a linear flow/density relationship that leads to a constant speed for upstream 'shock' waves. This form of relationship was proposed by Duncan [11] and supported by Banks [12], both on empirical grounds and because it follows from assuming vehicles maintain a safe spacing to avoid collision in the event of an emergency stop. Arguably these together represent the simplest model of traffic that can give realistic aggregate behaviour, although it does not attempt to account for the fine details of real traffic behaviour.

Referring to Fig. 2, on the upstream section (a) where the arriving traffic $q_{a}$ is assumed to be uncongested, the average speed $v_{a}$ is given by the following linear relationship, where $V_{f}$ is the free flow speed and $\alpha$ is a speed/flow slope parameter intrinsic to uncongested traffic behaviour:

$v_{a}=V_{f}-\alpha q_{a}, \quad \rho_{a}=\frac{q_{a}}{v_{a}}$

Behaviour in congestion where car-following dominates is unrelated to that in uncongested flow where overtaking is possible. Within the queue (b) speed, density and flow are related by:

$$
v_{b}=\frac{\lambda q_{b}}{n-\tau q_{b}{ }^{b}}, \quad \rho_{b}=\frac{q_{b}}{v_{b}}=\frac{n-\tau q_{b}}{\lambda}
$$




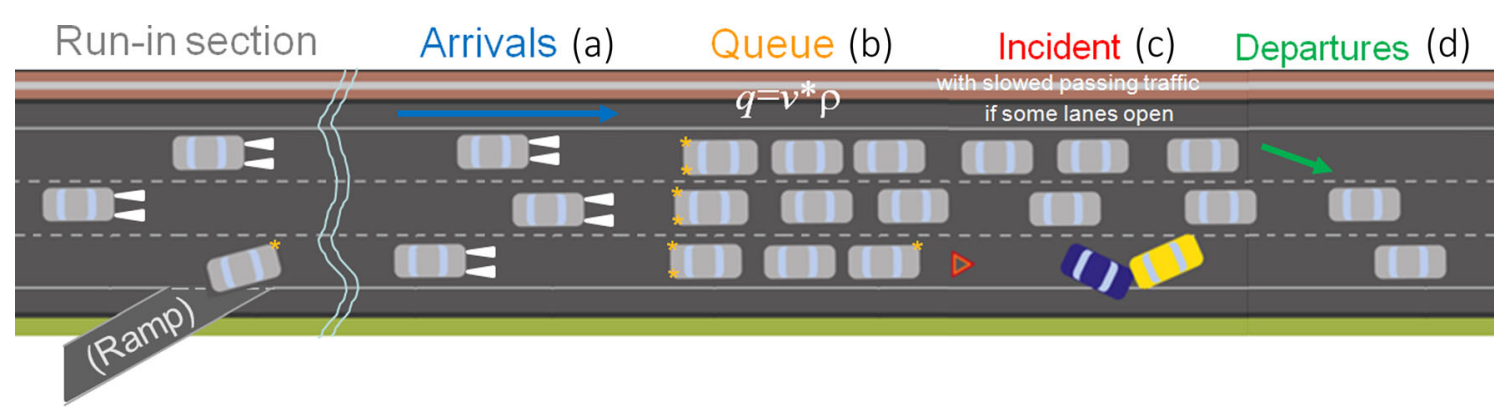

Fig. 2 Schematic system configuration for describing traffic states around an incident

where $n$ is the number of lanes available to the queue, ${ }^{5}$ normally equal to the usual number of running lanes, and $\lambda$ and $\tau$ are proxy measures of jam spacing and driver response time respectively, such that the upstream wave speed, also the slope of the flow/density relationship, is given by:

$w=-\frac{\lambda}{\tau}$

The simple complete traffic model requires that the two relationships meet at a point of 'critical density' representing practical capacity at a realistic speed. At this point $v_{a}=v_{b}$ and flow is equal to $n \mu$, where $\mu$ is the normal capacity per lane. In practice, some spontaneous loss of capacity is sometimes observed around this point, which can be allowed for approximately by adjusting the slope of the 'uncongested' relationship by a factor $\beta$ (typically in the range 1.00-1.15), thus:

$\alpha=\frac{V_{f}-\frac{\lambda \mu}{1-\tau \mu}}{n \beta \mu}$

The build up and discharge of a simple queue at an incident, that reduces capacity below demand for a period of time, is sketched in Fig. 4. The speed of the 'tail-wave' where arriving traffic meets the queue is given by the continuity equation (an extension of the fundamental relationship):

$v_{a b}=\frac{q_{a}-q_{b}}{\rho_{a}-\rho_{b}}$

The tail of the queue propagates upstream as long as the blockage persists. From the time of Clearance of the incident, the queue starts to discharge from its head at the incident site, resulting in a discharge head wave that travels upstream. The maximum queue reach, where tail and head waves meet, depends on the speeds at which the waves propagate. The shape of the resulting queuing

\footnotetext{
${ }^{5}$ Could exceed normal number of lanes if hard shoulder is opened, while lanes available at incident may be fewer than normal.
}

region determines the maximum queue size (in vehicles) and extent (in distance), as shown, from which the total delay can be determined by geometry taking account of traffic density and speed. It has occasionally been observed that head and tail waves fail to meet, resulting in a persistent region of congested traffic propagating upstream. It is also observed that a queue can develop periodic 'jam waves', but such detail is not required here. This simplified 'horizontal' queue model differs significantly from an even simpler 'vertical' model that considers only the number of queuing vehicles. Arrival flow can vary with time as described earlier, although this is not represented in the Figure.

\subsection{Capacity adjustments in and around the queue}

When an incident is present, the capacity determining flow in the queue may be reduced locally through a reduction in the number of lanes available from $n$ to $m$, and a reduction in average lane capacity, represented by a factor $\chi$, arising from speed limit, police presence or 'lateral discomfort':

$q_{b}=q_{c}=\chi^{m \mu}$

The factor $\chi$ has been found empirically to depend on the number of available lanes [13]. Speed and density within the queue (b) are estimated using the relationships detailed above. The number of lanes available to the queue is assumed to be the normal number of carriageway lanes, although it could be adjusted to allow, for example, for opening the hard shoulder to accommodate more traffic, or reserving a lane for exiting traffic. Reduced speed of traffic passing the incident (c) may incur extra delay, but is neglected here as the zone is assumed to be short (as opposed to with an extended obstruction like road works or when overtaking a large slow convoy such as an abnormal load). The queue discharge head wave speed $v_{b d}$ is assumed to equal the 'shock' wave speed $w$ given by Eq. (4), because it is depends essentially on the internal dynamics of the queuing traffic. This applies also to boundaries within the queue where the traffic state 
Table 2 List of variables used in this paper

\begin{tabular}{|c|c|c|c|}
\hline Symbol & Definition & Units & Notes \\
\hline$m, n$ & Number of lanes & & Available or normal number of lanes according to context \\
\hline$\mu$ & Lane capacity & $\mathrm{PCU} / \mathrm{h}^{\mathrm{a}}$ & Normal capacity of one lane for flowing traffic \\
\hline$q$ & Flow & $\mathrm{veh} / \mathrm{h}$ & May be subscripted corresponding to sections in Fig. 2 \\
\hline$\rho$ & Density & $\mathrm{veh} / \mathrm{km}$ & $k$ is also commonly used \\
\hline$v$ & Speed & $\mathrm{km} / \mathrm{h}$ & Strictly space-mean, though time-mean is often measured ${ }^{b}$ \\
\hline$V_{f}$ & Free-flow speed & $\mathrm{km} / \mathrm{h}$ & Maximum speed with no other traffic \\
\hline$\rho_{c}$ & Critical density & $\mathrm{veh} / \mathrm{km}$ & Point at which flow breaks down and congestion starts \\
\hline$v_{c}$ & Critical speed & $\mathrm{km} / \mathrm{h}$ & Corresponding to critical density \\
\hline$\rho_{\max }$ & Jam density & $\mathrm{veh} / \mathrm{km}$ & Notional density at which speed is zero ( $k_{j}$ sometimes used) \\
\hline$\alpha$ & Speed/flow slope & $\mathrm{km} / \mathrm{veh}$ & Determines how speed decreases with flow if uncongested \\
\hline$\lambda$ & Jam spacing & $\mathrm{m}$ & Effective minimum road space required by vehicle \\
\hline$\tau$ & Response time & $\mathrm{sec}$ & Effective reaction and response time of driver \\
\hline$w, w_{f}$ & Wave speed & $\mathrm{km} / \mathrm{h}$ & Speed at which a disturbance propagates upstream \\
\hline$\beta, \gamma, \chi$ & Capacity factors & & Parameters used to adjust lane capacities for calibration \\
\hline$\delta_{i}$ & Diversion factors & & Diversion could vary with time (not used in modelling) \\
\hline$v_{i j}$ & Wave speeds & $\mathrm{km} / \mathrm{h}$ & Speeds of propagation of state boundaries in queue \\
\hline$r_{i}$ & Queue reach & $\mathrm{km}$ & Upstream position of tail of queue at various times \\
\hline$t_{i}$ & Event times & $\mathrm{h}$ & Times at which traffic or queue state changes \\
\hline$X$ & Max. queue extent & $\mathrm{km}$ & Maximum length of queue, head to tail \\
\hline$R$ & Max. queue reach & $\mathrm{km}$ & Maximum distance of queue tail from incident site \\
\hline$S_{i}$ & Time-space 'area' & $\mathrm{km}-\mathrm{h}$ & Measure of amount of queuing in a given period \\
\hline$D$ & Total delay & veh-h & Allows for time that would have been taken at free-flow \\
\hline
\end{tabular}

${ }^{\text {a }}$ Converting PCU/h (Passenger Car Unit) to veh/h depends on average PCU factor in traffic, here assumed $=1$

${ }^{\mathrm{b}}$ Space-mean speed is averaged over an amount of distance rather than time. This differs from 'time-mean' speed, as often measured, only if there is a distribution of speeds in the traffic, neglected here to first approximation changes. Downstream of the incident site (d) it is assumed that the same uncongested relationship (2) between speed, flow and density applies as on the arrival section (a), and the normal number of lanes is available, although their capacity may be reduced by a factor $\gamma$ to allow for speed initially being lower than free-flow speed.

$q_{d(\max )}=\gamma n \mu$

Fig. 3 Speed-flow-density behavioural relationships adopted in modelling

\subsection{Propagation speed of queue head-wave and other disturbances}

While the propagation speed of the tail-wave of a queue can be obtained explicitly using Eq. (6), because arrival and queuing flows are independent, this is not the case at the head of the queue or at virtual boundaries between different traffic states within the queue. Consequently the head-wave speed is
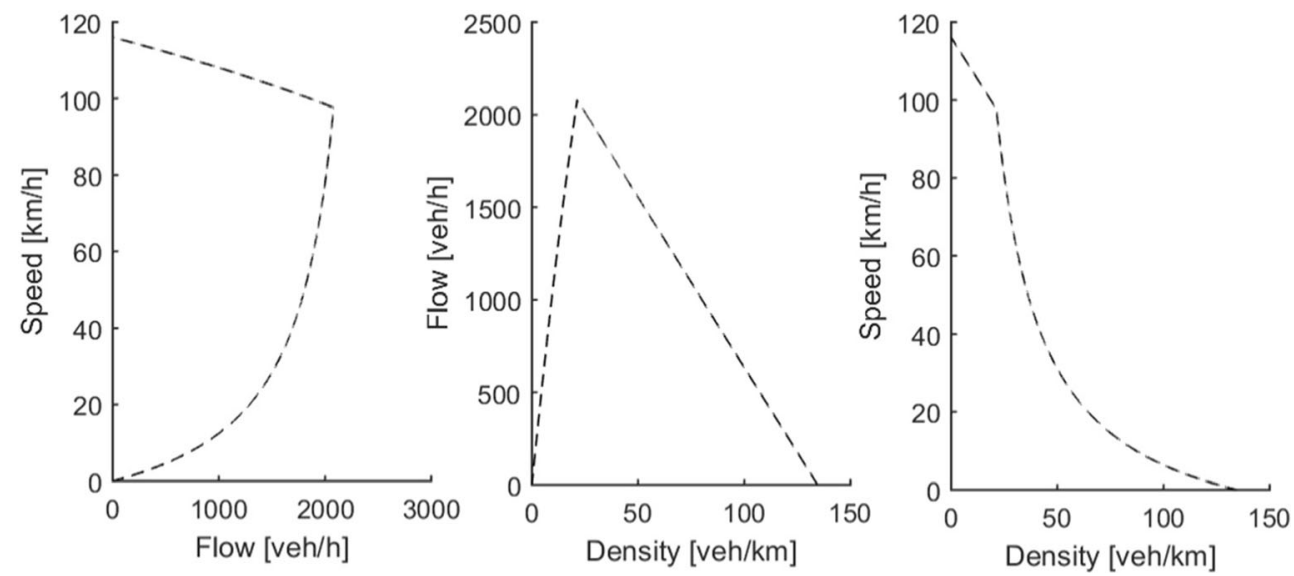
Fig. 4 Sketch of development and discharge of a simple queue showing essential elements

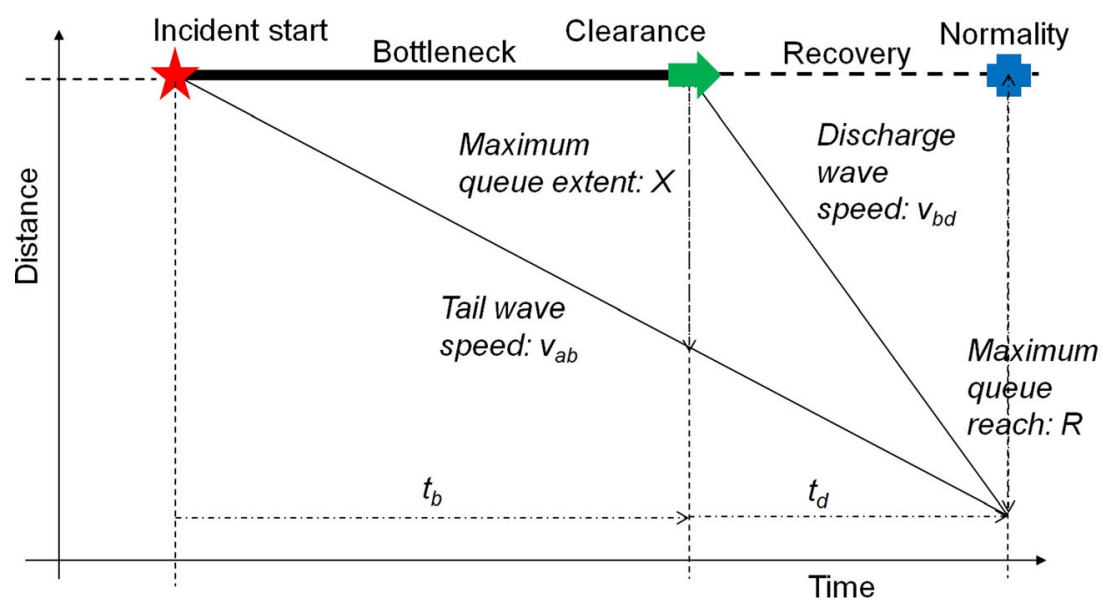

indeterminate. In theory, the speed at which a disturbance propagates in a queue is given by the slope $d q / d \rho$ of the flow/density relationship (middle graph in Fig. 3), which can vary with traffic state depending on the shape of the relationship. However, within a traffic column, a vehicle's motion is influenced essentially by the one in front, and the speed and spacing of both can vary considerably on short time scales ('stop-start'). So representing the traffic state by a single point on the graph is an idealisation. Quicker moving disturbances will tend to catch up and merge with slower ones. An average head-wave speed may emerge from these effects in a way a simple model cannot describe. Head-wave speed arises naturally in the CTM simulation, but the current version of the queue model is unable to estimate it dynamically as this would require an iterative process. So it is assumed to equal the intrinsic wave speed in Eq. (4) which depends only on the jam spacing and response time parameters. However, this can affect results only when capacity varies between different phases of the incident.

\subsection{Modelling queue and delay across several incident phases}

An actual incident may progress through several phases in which traffic capacity can vary, for example through a change in the number of lanes available. The demand can also vary with time, either autonomously or because of diversion (although diversion is not applied in this project). This is represented by dividing the modelled queue into segments as shown in Fig. 5. In this case the discharge head-waves are replaced by virtual boundaries where traffic conditions change. The multi-phase model takes account of the several phases of incident management in which the number of lanes available may change, the output from the queue in one period feeding into the input of the next. The incident is assumed to consist of the four phases shown in Fig. 5, plus a possible 'Respite' period (Section 2.1), with up to six event times $\left\{t_{i}: i=0 \ldots 5\right\}$ representing the start and end times of the phases. The number of lanes free at the incident site in each phase is $\left\{m_{i}: i=0 \ldots 5\right\}$ and the number available to the queue $\left\{n_{i}: i=0 \ldots 5\right\}$, assumed normally to equal the number of running lanes.

Arrival volume can change with time in a manner unrelated to the incident phases, resulting in changes in the queue's tailwave speed. Also, because changes propagate through a queue at finite speed, changes at its tail are delayed relative to causative changes at its head and vice-versa. These effects are difficult to model using constant values in fixed time periods, because each phase would need to be divided into many sub-phases in which some values change, leading to complexity comparable with that of a CTM. Some allowance can be made by averaging the 15-min arrival flows appropriately to give representative arrival rates for each phase calculation. Assuming that these have been established, and throughput in each queuing phase is at capacity, the calculation of flow, speed and density in each phase $i$ follow Eqs. (1), (2), (3), (4), (5) and (6), with tail-wave speeds given by:

$v_{i-1, i}=\frac{q_{a i}-q_{b i}}{\rho_{a i}-\rho_{b i}}$

As explained above, speeds at virtual boundaries in the queue are assumed to equal the wave speed $w$ given by Eq. (4). The point $r_{i}$ at which head and tail waves meet, measured from the head of the queue, is obtained by geometry, remembering that upstream distance and speed values are negative. For the first (triangular) segment:

$r_{1}=\frac{t_{1}-t_{0}}{v_{0,1}^{-1}-v_{1,1}^{-1}}$

Moving to the next queue segment, the geometry is in general quadrilateral:

$r_{2}=\frac{\left(t_{2}-t_{1}\right)-r_{1}\left(v_{11}^{-1}-v_{12}^{-1}\right)}{v_{12}^{-1}-v_{22}^{-1}}$ 
Fig. 5 Queue development through four phases of an incident modelled by several segments

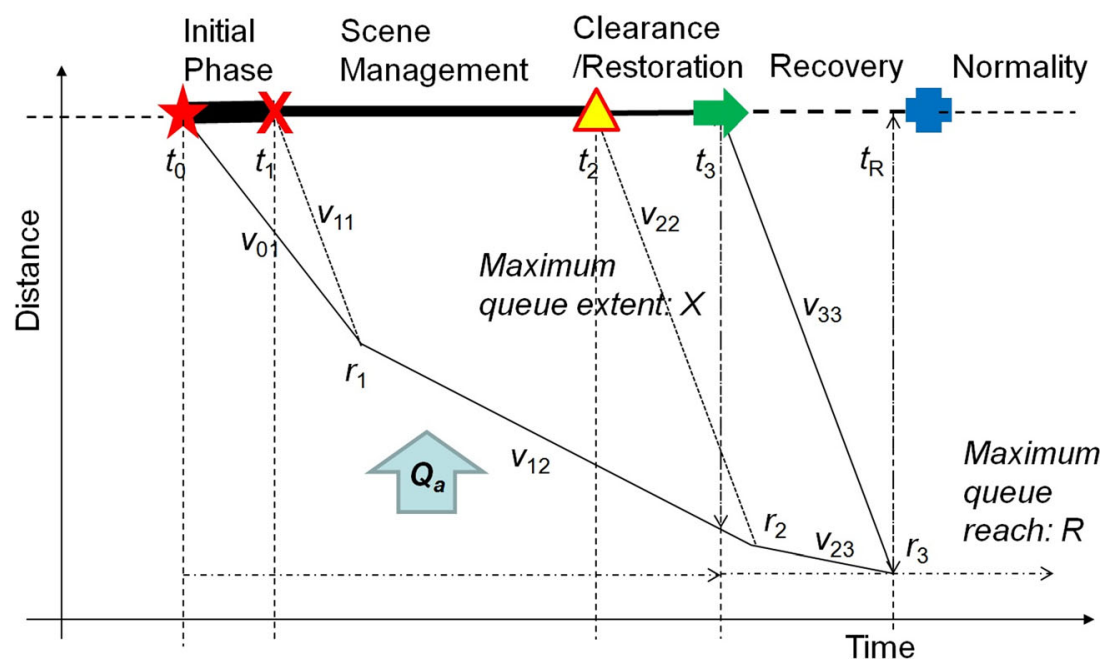

and so forth. The maximum upstream reach of the queue is then:

$R=\max \left(r_{i}\right)$

The total queued space-time 'area' is each phase is obtained by the 'average height times base' rule for the area of a triangle or parallelogram:

$S_{i}=\frac{1}{2}\left(r_{i-1}+r_{i}\right)\left(t_{i-1}-t_{i}\right)$

To obtain aggregate delay in veh-h this must be multiplied by vehicle density and adjusted for the difference in speed between queuing and free flow. These delays are then summed to give the total queuing delay, where $N$ is the number of phases:

$D=\sum_{i=1}^{i=N} S_{i} \rho_{b(i)}\left(1-\frac{v_{b(i)}}{v_{a(i)}}\right)$

\subsection{Implementation of CTM-v simulation}

The method adopted for detailed simulation is the velocitybased Cell Transmission Model (CTM-v) of Daganzo [14] as used in the Mobile Millennium Stockholm project, which assimilated knowledge developed in the Mobile Millennium project at the University of California at Berkeley [15]. This implementation of the CTM was chosen in order to allow for straightforward transfer of results from the PRIMA project into the travel time prediction algorithms used in the Mobile Millennium platform. Like the queue model, formulation of CTM starts from the Fundamental Relationship between flow, speed and density, Eq. (1), in a form where speed is expressed as an explicit function of density $V(\rho)$ where density is assumed to be a function of position and time $\rho(x, t)$ taking values between 0 and $\rho_{\max }$. For the practical implementation of CTM-v the model needs to be invertible, density being expressible in terms of speed. Density is obtained by inverting a hyperbolic linear approximation to the Daganzo-Newell speed function, giving:

$\rho=V_{H L}^{-1}(v)=\left\{\begin{array}{cl}\rho_{\max }\left(1-\frac{v}{v_{\max }}\right) & \text { if } v \geq v_{c} \\ \rho_{\max }\left(\frac{1}{1+\frac{v}{w_{f}}}\right) & \text { if } v<v_{c}\end{array}\right.$

Traffic dynamics are assumed to obey the partial differential equation (PDE) of Lighthill and Whitham [16] and Richards [17] (LWR), which for the purpose of computation is discretised using the scheme of Godunov [18]. Details about the CTM-v model and the discretisation are given in Work et al. [19].

\subsection{A simple method of allowing for diversion}

Although diversion has not been used in the incident scenarios modelled, the queue model provides for it based on a simple equilibrium principle. In practice some traffic might be diverted by the TMC or police, or spontaneously as a result of information received upstream through broadcast or VMS, and the amount of diversion could vary between phases. If the proportion of traffic diverted in phase $i$ is $\delta_{i}$ the flow arriving at the queue is reduced by the factor $\left(1-\delta_{i}\right)$, leading to an appropriate reduction in the queue and delay at the incident being modelled. While it is not possible to estimate delay in the surrounding network without extending the model and involving considerable extra detail, a rational simplifying assumption is that equilibrium obtains between incident and diversion route(s), meaning equal delay to individual vehicles, so the modelled total delay in the queue and number of vehicles directly affected should be factored up by $1 /\left(1-\delta_{i}\right)$ to give 
estimates for the whole network. As queuing delay is roughly quadratic with demand while the equilibrium adjustment is linear, diversion can reduce total delay in the network as well as delay at the incident itself. On the other hand, authorities may choose not to divert heavy traffic from a high-capacity road because of the risk of causing severe congestion and secondary accidents on a local network unsuitable for high volumes.

\subsection{Summary of differences between queue model and CTM-v}

The most important differences between the models are summarised in Table 3.

\section{Calibration and implementation}

Traffic and incident simulation has been done on networks specifically designed to support the four incident scenarios listed in Section 2, with characteristics given in Table 4. The networks are straight motorway sections with 2 or 3 lanes extended to $100 \mathrm{~km}$ to ensure that queues are contained in the modelled road section.

The CTM model parameters are calibrated using data from Swedish motorways. For the 2-lane road with speed limit $120 \mathrm{~km} / \mathrm{h}$ the calibration results in $\rho_{\max }=134.5$ vehicles/ lane-km, $v_{\max }=116 \mathrm{~km} / \mathrm{h}$ and $w_{f}=18.4 \mathrm{~km} / \mathrm{h}$ upstream, which gives a capacity of 2080 vehicles/h/lane, a critical density of 21.3 vehicle/lane $/ \mathrm{km}$ and a critical speed of $97.7 \mathrm{~km} / \mathrm{h}$. For the 3-lane road with speed limit $80 \mathrm{~km} / \mathrm{h}$ the calibration results in $\rho_{\text {max }}=134.5$ vehicles $/$ lane-km, $v_{\max }=80 \mathrm{~km} / \mathrm{h}$ and $w_{f-}$ $=17 \mathrm{~km} / \mathrm{h}$ upstream, which gives a capacity of 1867 vehicles/h/lane, a critical density of 28.6 vehicle/lane-km and a critical speed of $62.9 \mathrm{~km} / \mathrm{h}$. The parameters $\lambda$ and $\tau$ in the macroscopic queue model speed-density-flow relationships are calibrated to fit the relationships used in the CTM. For the 2-lane road with speed limit $120 \mathrm{~km} / \mathrm{h}$ this gives $\lambda=$ $7.43 \mathrm{~m}$ and $\tau=1.45 \mathrm{~s}$. For the 3-lane road with speed limit of $80 \mathrm{~km} / \mathrm{h}$ the calibration gives very similar values $\lambda=7.43 \mathrm{~m}$ and $\tau=1.49 \mathrm{~s}$. Cell length of $243 \mathrm{~m}$ is based on the standard value used in the Mobile Millennium Stockholm implementation of the CTM-v. This cell length allows free flow speeds up to $40 \mathrm{~m} / \mathrm{s}(144 \mathrm{~km} / \mathrm{h})$, well in excess of any speed modelled, while ensuring that traffic cannot traverse a whole cell in one $6 \mathrm{~s}$ time step.

\subsection{Capacity reduction in the vicinity of an incident}

Incidents not only reduce road capacity by blocking shoulders or lanes but often also affect the capacity of the other lanes, through narrowing, speed reduction or 'lateral discomfort'. Lane capacity reduction factors are required in order to capture this effect. Unfortunately there appear to be few investigations on this topic. The reductions applied are those recommended in the Highway Capacity Manual [13] which describes lane capacity reduction in terms of utilisation of remaining capacity, as given in Table 5 .

The effect of the capacity reduction is modelled by changing the number of lanes available, allowing fractions. The implementation applies the common behavioural diagrams to each individual lane, but as aggregate flow and density, unlike speed, depend on the number of lanes, the aggregate behavioural diagrams change, and free flow speed may also be reduced. HCM [13] gives only estimates on how the capacity is effected and not the relationship between flow and density. In this work we have assumed that the jam and critical densities are not affected by the capacity utilisation. These assumptions imply decreased critical and free flow speed with decreasing capacity utilisation, i.e. drivers desire to pass at a slower speed if more lanes are blocked. The effect of capacity reductions on the relationships is shown in Fig. 6.

Table 3 Main assumptions in and differences between the modelling methods

\begin{tabular}{|c|c|c|}
\hline Context & Queue model & CTM-v simulation \\
\hline Time dynamics & $\begin{array}{l}\text { Resolves only to the level of TIM phases, allowing } \\
\text { different but constant arriving and capacity flows } \\
\text { within each phase, with arrivals obtained by } \\
\text { averaging } 15 \text {-min profile values. }\end{array}$ & $\begin{array}{l}\text { Discrete time model with } 6 \mathrm{~s} \text { time steps enabling not } \\
\text { only detailed modelling of variations in capacity, } \\
\text { demand and arriving flow over time, but also detailed } \\
\text { modelling of changes in traffic dynamics. } \\
\text { Demand is profiled with } 15 \text {-min resolution. }\end{array}$ \\
\hline Space dynamics & $\begin{array}{l}\text { Considers one homogeneous road section, or more } \\
\text { precisely one incident site of unspecified size. } \\
\text { The only spatial modelling is of queue extent. } \\
\text { Off- and on-ramps are not modelled. }\end{array}$ & $\begin{array}{l}\text { Divides the road section into cells in which the road } \\
\text { characteristics may vary, enabling handling of } \\
\text { exiting and entering traffic on off- and on-ramps. }\end{array}$ \\
\hline Traffic dynamics & $\begin{array}{l}\text { Assumes that vehicle density changes instantly at } \\
\text { each queue segment boundary (see Fig. 5). } \\
\text { Neglects any delay due to reduced speed in traffic } \\
\text { passing the incident or dispersing downstream. }\end{array}$ & $\begin{array}{l}\text { Assumes that vehicle density is constant in each cell } \\
\text { during each time step but can vary between cells } \\
\text { and time steps. }\end{array}$ \\
\hline
\end{tabular}


Table 4 Summary of characteristics of test networks

\begin{tabular}{lll}
\hline Attribute & Network 1 & Network 2 \\
\hline Test scenarios using network & S1: Collision & S2: Weather incident \\
& S3: LGV breakdown & S4: Obstruction \\
Number of lanes & 3 & 2 \\
Length of simulation network & $100 \mathrm{~km}$ & $100 \mathrm{~km}$ \\
Speed limit/free speed $\left(v_{\max }, V_{f}\right)$ & $80 \mathrm{~km} / \mathrm{h}$ & $120 \mathrm{~km} / \mathrm{h}$ \\
Normal lane capacity $(\mu)$ & $1867 \mathrm{veh} / \mathrm{h} /$ lane & $2080 \mathrm{veh} / \mathrm{h} / \mathrm{lane}$ \\
Effective vehicle spacing $(\lambda)$ & $7.43 \mathrm{~m}$ & $7.43 \mathrm{~m}$ \\
Effective response time $(\tau)$ & $1.49 \mathrm{~s}$ & $1.45 \mathrm{~s}$ \\
Time step in CTM $(\Delta t)$ & $6 \mathrm{~s}$ & $6 \mathrm{~s}$ \\
Length of cells in CTM $(\Delta x)$ & $243 \mathrm{~m}$ & $243 \mathrm{~m}$ \\
\hline
\end{tabular}

\subsection{Modelling of VMS with variable speed limit}

For scenario 2 (weather event) one technique is to use Variable Message Signs (VMS) to avoid closing any lanes but decrease the operating speed at the scene by a temporary lower speed limit. The effect of the lower speed limit has been modelled by adjusting the free flow speed in the speed density relationship assuming no effect on critical or maximum density. When using the hyperbolic speed-density relationship (15), these assumptions are equivalent to a capacity utilisation of $43 \%$. This is a simple way of modelling the effects that do not take drivers' compliance with temporary speed limits into account. The modelling would benefit from further empirical investigations into how temporary speed limits at incident site where safe operating speed is reduced influence drivers' speed choice and the speed-density relationship. However, the simplification is considered to have only a minor effect on the comparison of the queue model with CTM-v, as the effect is modelled similarly through the speed-density relationship.

\subsection{Handling of time-varying traffic profiles}

Both average arrival flow and capacity may change between the different phases. As described earlier, traffic arrivals are defined by several time-varying profiles resolved to $15 \mathrm{~min}$. Profiles are input directly to the CTM simulation, but the macroscopic queue model averages the data to give a single value of arriving flow in each phase of the incident. Because this affects the point in space and time at which the tail and discharge waves meet, the points $r_{i}$ in Fig. 5, which in turn affects the exact timing of arrivals at the queue, an iterative script is used to obtain an equilibrium between them. A practical issue is that the queue model does not automatically take account of the offset in timing between the profiles of traffic entering the network and arriving at the back of the queue at the incident site. Figure 7 shows an example of the differences between these demand profiles. This can be resolved to an extent by adjusting the profile supplied to the queue model, as described later.

\subsection{Including the impact of novel technology}

It is assumed that the principal effect of novel technology will be felt in the Discovery and Verification and possibly the Initial Response phases of the incident, for example through rapid detection by Advanced eCall or an intelligent monitoring system. The precise nature of the technology is not specified as the relevant factor is its impact on average response time.

\subsection{Running multiple scenario combinations in queue model}

The macroscopic queue model is implemented in an Excel spreadsheet, taking advantage of the software's transparency and presentational facilities. A script has been developed to allow automation of the calculation of combinations of incident scenarios, scene management techniques, and time savings expected from novel technologies, all results being collected in separate worksheets for ease of analysis.

Table 5 Utilisation of remaining capacity

\begin{tabular}{lllllllll}
\hline $\begin{array}{l}\text { Lanes on } \\
\text { freeway }\end{array}$ & $\begin{array}{l}\text { No } \\
\text { incident }\end{array}$ & $\begin{array}{l}\text { Rubbernecking } \\
\text { small }\end{array}$ & $\begin{array}{l}\text { Rubbernecking } \\
\text { large }\end{array}$ & $\begin{array}{l}\text { Shoulder } \\
\text { disable }\end{array}$ & $\begin{array}{l}\text { Shoulder } \\
\text { accident }\end{array}$ & $\begin{array}{l}1 \text { lane } \\
\text { blocked }\end{array}$ & $\begin{array}{l}2 \text { lanes } \\
\text { blocked }\end{array}$ & $\begin{array}{l}3 \text { lanes } \\
\text { blocked }\end{array}$ \\
\hline 2 & $100 \%$ & $95 \%$ & $75 \%$ & $95 \%$ & $81 \%$ & $70 \%$ & $0 \%$ & N/A \\
3 & $100 \%$ & $95 \%$ & $75 \%$ & $99 \%$ & $83 \%$ & $74 \%$ & $51 \%$ & $0 \%$ \\
\hline
\end{tabular}



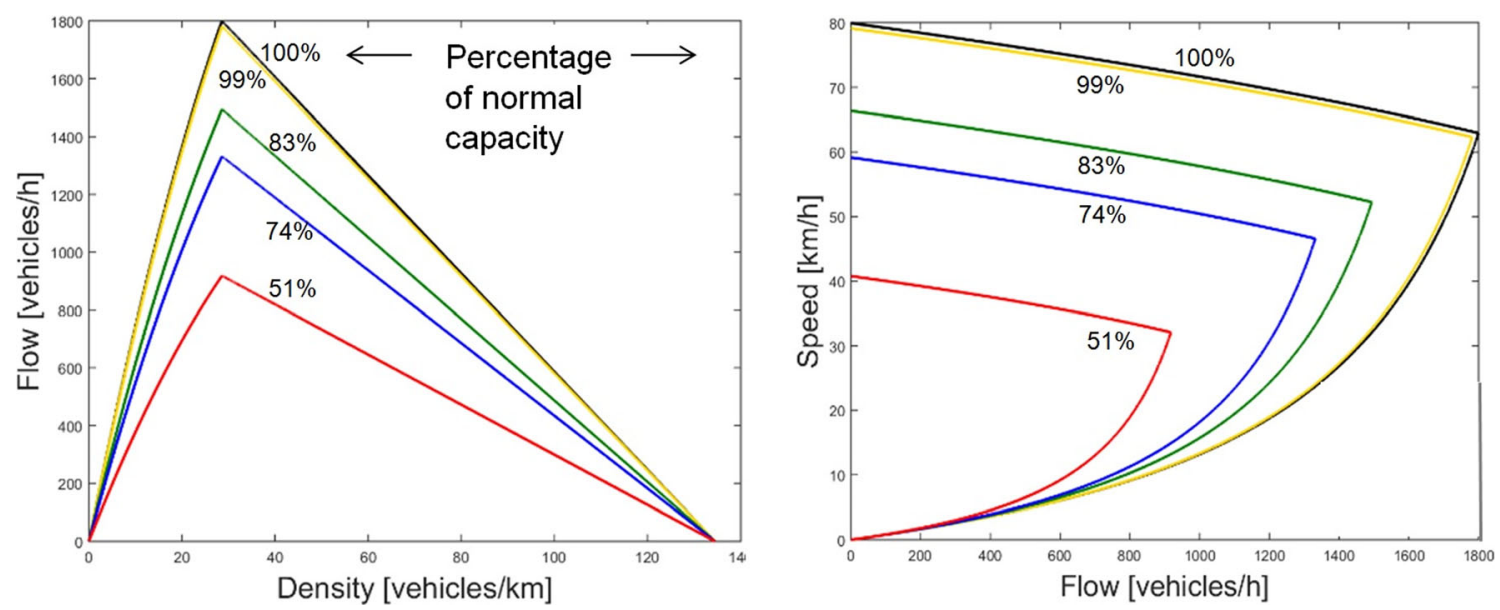

Fig. 6 Aggregate flow-density (left) and speed-flow (right) relationships for different capacity utilisation in Scenarios 1 and 3 (note: per-lane densityspeed relationship does not change)

\section{Verification of methods and comparison of results}

This Section compares results of selected simulations using the velocity-based Cell Transmission Model (CTMv) with calculations using the macroscopic queue model. Test cases are selected from the scenarios, management techniques, peak profiles and technology options. Tests with comparison of model results are presented in an order that reflects increasing case complexity rather than numbering:

- Section 5.1 considers incidents and techniques that include one scene management period (no respite period) and constant traffic demand.

- Section 5.2 considers scenarios and techniques that include one scene management period but for which the traffic demand varies over time.

- Section 5.3 considers techniques that involve two periods of scene management or clearance separated by a respite period.

- Section 5.4 compares results of applying the macroscopic simulation model and the queue model for all scenarios and techniques with one level of demand profile.

\subsection{One scene management period with constant demand}

This section considers first a basic case for which the queue model should be able to give similar predictions as the more detailed macroscopic simulation model. In this example of Scenario 4 (Obstruction) managed by Technique 1 (Close all lanes), constant traffic demand is assumed and ramps are not modelled. Figure 8 a shows the result of the simulation, where the colours indicate traffic speeds as defined by the bar at the right, while the superimposed white lines show the boundaries of the queue calculated by the queue model. The reduced speed of traffic departing the queue reflects its higher flow and density compared to traffic arriving at or unaffected by the incident. In practice there would be gradual acceleration and some dispersion, but observations of real bottleneck queues (e.g. [20]) show that dense traffic can persist for tens of kilometres downstream of a bottleneck. There is good agreement between the regions of densest queuing in simulation and queue model.

A more comprehensive comparison of Scenario 4 (Obstruction) is represented in Table 6 giving the total delay, queue extent and duration over three TIM
Fig. 7 Traffic flow measured at incident location compared with demand entering the network

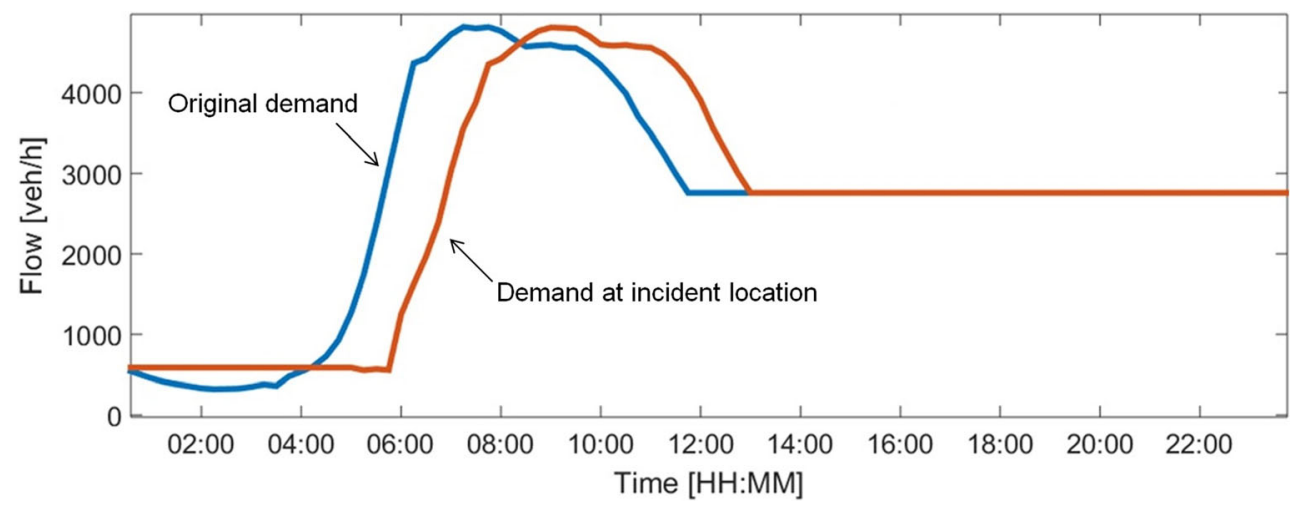


Fig. 8 Comparing traffic state estimations using CTM-v simulation and macroscopic queue modelling for several cases with one scene management period

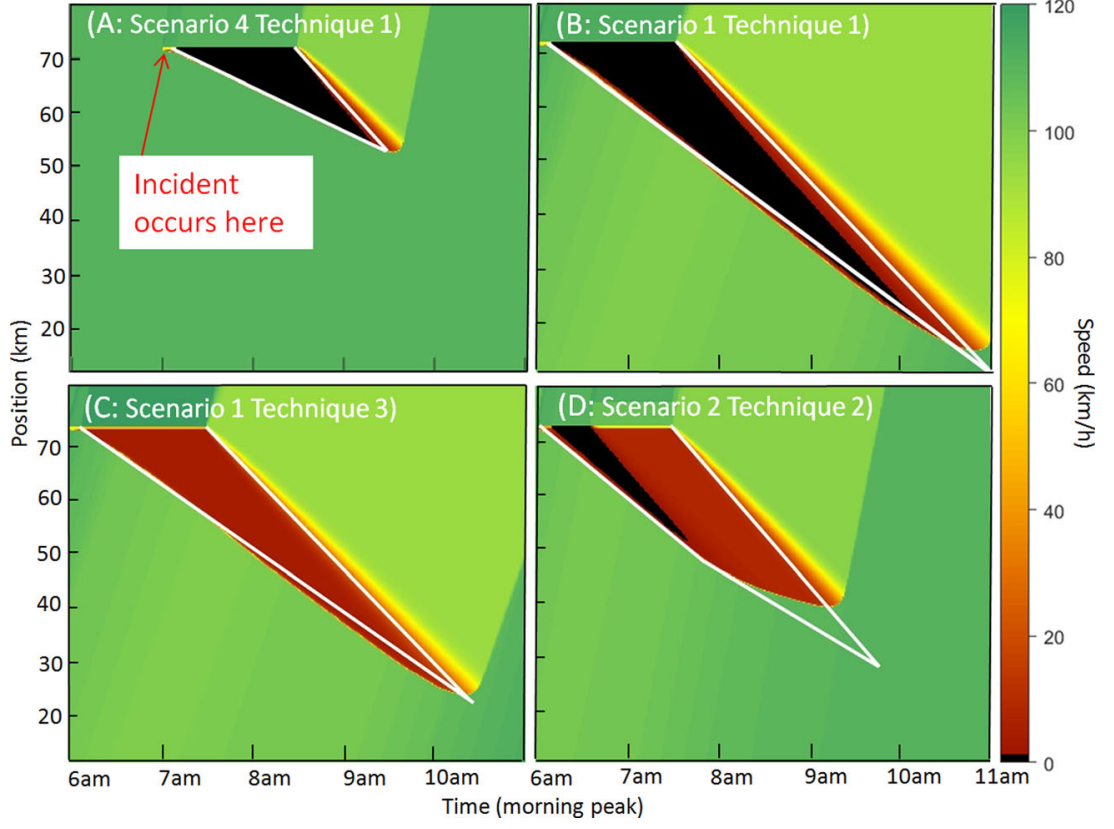

techniques. The results confirm that the total queue extent and duration estimated by the queue model are broadly similar to those simulated by CTM. However, there are significant differences between the total delays.

Table 7 gives the results when comparing only the most congested regions represented in Fig. 8a by the darker areas (black and red). It is evident that comparing only heavily congested regions shows better agreement between the methods. The reason is that the queue model neglects road length, while the CTM simulation represents a road section extending both upstream and downstream of the incident location and thereby includes the delay incurred downstream of the incident site. Furthermore, the queue model assumes instant changes in density at the boundaries between queue segments while the simulation models a smoother change of density when the recovery wave propagates upstream. Accordingly, subsequent comparisons are restricted to the heavily congested regions, that is the main queue upstream of the incident location.

\subsection{One scene management period with time-varying demand}

Time-varying demand profiles, apart from adding realism, enable evaluation of TIM techniques which take advantage of changes in arrival rate to apply actions that may cause major capacity reduction in the off-peak rather than the peak. A simulation of Scenario 1 (Collision) with time-varying traffic demand profile is shown in Fig. 8b, where the simplest Technique 1.1 (Close all lanes) is applied. Table 8 gives performance indicators for all the TIM techniques used for this Scenario.

In this case the queue model overestimates congestion regardless of technique. This is again traceable to the fact that CTM simulates an extended road section while the queue model assumes a single incident location. In this case the effect is opposite to that in the previous test because CTM is able to model a variable arrival rate to the queue depending on the location of the queue tail, which is in general not equal to the traffic demand profile entering the road section, as the
Table 6 Comparing incident estimations simulated by CTM and queue model for Scenario 4 (Obstruction), taking account of all locations where delay may occur

\begin{tabular}{lllll}
\hline Simulation tool & TIM technique & $\begin{array}{l}\text { Total delay } \\
{[\text { veh-h }]}\end{array}$ & $\begin{array}{l}\text { Max queue extent } \\
{[\mathrm{km}]}\end{array}$ & $\begin{array}{l}\text { Total duration } \\
{[\mathrm{h}]}\end{array}$ \\
\hline CTM & 4.1 (close all lanes) & 4912 & 20 & 2.6 \\
Queue model & 4.1 (close all lanes) & 3764 & 20 & 2.6 \\
CTM & 4.2 (contraflow) & 2323 & 11 & 2.1 \\
Queue model & 4.2 (contraflow) & 1909 & 11 & 2.1 \\
CTM & 4.3 (close blocked lane) & 1070 & 6 & 2.0 \\
Queue model & 4.3 (close blocked lane) & 1024 & 7 & 2.0 \\
\hline
\end{tabular}


Table 7 Comparing incident estimations simulated by CTM-v and queue model for Scenario 4 (Obstruction), comparing only congested locations upstream of the incident

\begin{tabular}{lllll}
\hline Simulation tool & TIM technique & $\begin{array}{l}\text { Total delay } \\
{[\text { veh-h] }}\end{array}$ & $\begin{array}{l}\text { Max queue extent } \\
{[\mathrm{km}]}\end{array}$ & $\begin{array}{l}\text { Total duration } \\
{[\mathrm{h}]}\end{array}$ \\
\hline CTM & 4.1 (close all lanes) & 3764 & 20 & 2.6 \\
Queue model & 4.1 (close all lanes) & 3764 & 20 & 2.6 \\
CTM & 4.2 (contraflow) & 1974 & 11 & 2.1 \\
Queue model & 4.2 (contraflow) & 1908 & 11 & 2.1 \\
CTM & 4.3 (close blocked lane) & 999 & 6 & 2.0 \\
Queue model & 4.3 (close blocked lane) & 1024 & 7 & 2.0 \\
\hline
\end{tabular}

longer the queue is the earlier will a given block of demand reach it. However, the traffic profile fed into the queue model is the same as that entering at the start of the road section in the CTM simulation. This can be corrected by feeding the queue model with the exact flow profile at the location of the incident, while no incident is simulated. The results of such simulations are given in Table 9, and show improved agreement between the two methods.

The improvement in Table 9 is consistent with the fact that the correction minimises the extent of the queue, so the arrival flow at the tail of the queue is represented fairly well by the flow at the incident site itself, though the methods show less good agreement on queue extent than delay. In the CTM, arrival flow will be offset from the demand profile, as in Fig. 7, depending on the network, where as set up vehicles have to travel up to $73 \mathrm{~km}$ to reach the incident. Using the original time-varying demand profile as input to the queue model tends to cause overestimation of congestion in the initial phases compared to the CTM, while using the displaced demand profile as input to the queue model tends to result in overestimation of congestion in the later phases. The magnitude of the error depends mainly on the physical extent of the queue.

A way to overcome this may be to interpolate between the two demand profiles according to the queue extent in each separate phase of the incident, but a sensitivity analysis shows it is only a partial solution. For example, Technique 1.3
(Close some lanes) applied in Scenario 1 (Collision), plotted in Fig. 8c, has similar characteristics to Technique 2.2 (Contraflow) in Scenario 2 (Weather event), but the results differ. In the former case the queue model overestimates congestion by around $10 \%$ compared with the results from the CTM, although the difference in relative terms is moderate. For the latter case, plotted in Fig. 8d, the queue model overestimates delay by $17 \%$. This can be explained by the fact that it assumes a constant tail-wave speed in each phase segment according to Eq. (6) in Section 3, whereas the CTM simulation in this case allows the tailwave speed to vary within a phase.

\subsection{Two scene management periods with time varying demand}

Representing TIM techniques involving phases with reduced capacity over a long time period, usually related to the use of a respite period, for example in the quick clearance technique, could potentially cause a problem for the queue model. The reduction in average capacity available at the incident scene should be much less than would be the case during comprehensive action to clear the scene, avoiding the build-up of very large queues. However, accuracy of the demand profile becomes more important where a respite period is involved, as the queue model assumes a constant average demand during the whole
Table 8 Comparing incident estimations simulated by CTM-v and queue model for Scenario 1 (Collision), comparing only congested locations upstream of the incident

\begin{tabular}{lllll}
\hline Simulation tool & TIM technique & $\begin{array}{l}\text { Total delay } \\
{[\mathrm{veh}-\mathrm{h}]}\end{array}$ & $\begin{array}{l}\text { Max queue extent } \\
{[\mathrm{km}]}\end{array}$ & $\begin{array}{l}\text { Total duration } \\
{[\mathrm{h}]}\end{array}$ \\
\hline CTM & 1.1 (close all lanes) & 16,612 & 58 & 5.0 \\
Queue model & 1.1 (close all lanes) & 20,785 & 63 & 5.0 \\
CTM & 1.2 (incident screen) & 23,878 & 63 & 5.6 \\
Queue model & 1.2 (incident screen) & 28,503 & 69 & 5.7 \\
CTM & 1.3 (close some lanes) & 11,018 & 50 & 4.5 \\
Queue model & 1.3 (close some lanes) & 15,015 & 55 & 4.5 \\
CTM & 1.4 (Tow in off-peak) & 4101 & 33 & 4.9 \\
Queue model & 1.4 (Tow in off-peak) & 7243 & 45 & 5.0
\end{tabular}


Table 9 Comparing incident estimations simulated by CTM-v and queue model for Scenario 1 (Collision). Comparing only congested locations upstream of the incident and using traffic demand measured at the scene location

\begin{tabular}{lllll}
\hline Simulation tool & TIM technique & $\begin{array}{l}\text { Total delay } \\
{[\mathrm{veh}-\mathrm{h}]}\end{array}$ & $\begin{array}{l}\text { Max queue extent } \\
{[\mathrm{km}]}\end{array}$ & $\begin{array}{l}\text { Total duration } \\
{[\mathrm{h}]}\end{array}$ \\
\hline CTM & 1.1 (close all lanes) & 16,612 & 58 & 5.0 \\
Queue model & 1.1 (close all lanes) & 17,265 & 67 & 5.2 \\
CTM & 1.2 (incident screen) & 23,878 & 63 & 5.6 \\
Queue model & 1.2 (incident screen) & 23,941 & 73 & 5.7 \\
CTM & 1.3 (close some lanes) & 11,018 & 50 & 4.5 \\
Queue model & 1.3 (close some lanes) & 11,413 & 55 & 4.6 \\
CTM & 1.4 (Tow in off-peak) & 4101 & 33 & 4.9 \\
Queue model & 1.4 (Tow in off-peak) & 4066 & 33 & 5.0
\end{tabular}

period, which is likely to account for a large total volume of traffic. The effect of Technique 1.4 (Tow in off-peak) in Scenario 1 (Collision), which includes quick clearance during the initial phases followed by final clearance in the offpeak, is shown in Fig. 9a. In this case there is quite good agreement between the CTM and queue model.

The result of applying Technique 2.3 (VMS + Speed limit) in Scenario 2 (Weather event), simulated using a high and short traffic peak, is shown in Fig. 9b. Here the technique assumes that arriving traffic is forewarned and a mandatory or advisory speed limit applied. Quick clearance is not relevant, but there is still a respite period before final restoration of the scene (for example after snow or flood). In this case the queue model estimates higher congestion than the CTM because it does not allow for a reduction in the traffic demand during the extended duration of the incident.

This example demonstrates the limitations of the queue model when accounting for the precise traffic volumes arriving in TIM phases according to time-varying traffic demand. This arises not because arrivals cannot be averaged over any given period, but because of the difficulty of calculating the exact profile of arrivals at the queue tail whose position itself affects the timing of arrivals. The CTM is able to capture this detail because it simulates at much finer time resolution. On the other hand, the computational complexity of the CTM limits its ability to explore a large number of scenario and technique combinations, so a compromise may be necessary.

\subsection{Comparing the methods in all test cases}

Detailed comparisons of the results from simulations with CTM-v and calculations using the queue model have been conducted for 178 combinations of scenarios, techniques, demand profiles, speed limits and novel technology impacts. The principal combinations and results are given in Table 10.
Fig. 9 Comparing traffic state estimations using CTM-v simulation and macroscopic queue modelling for cases with two scene management periods

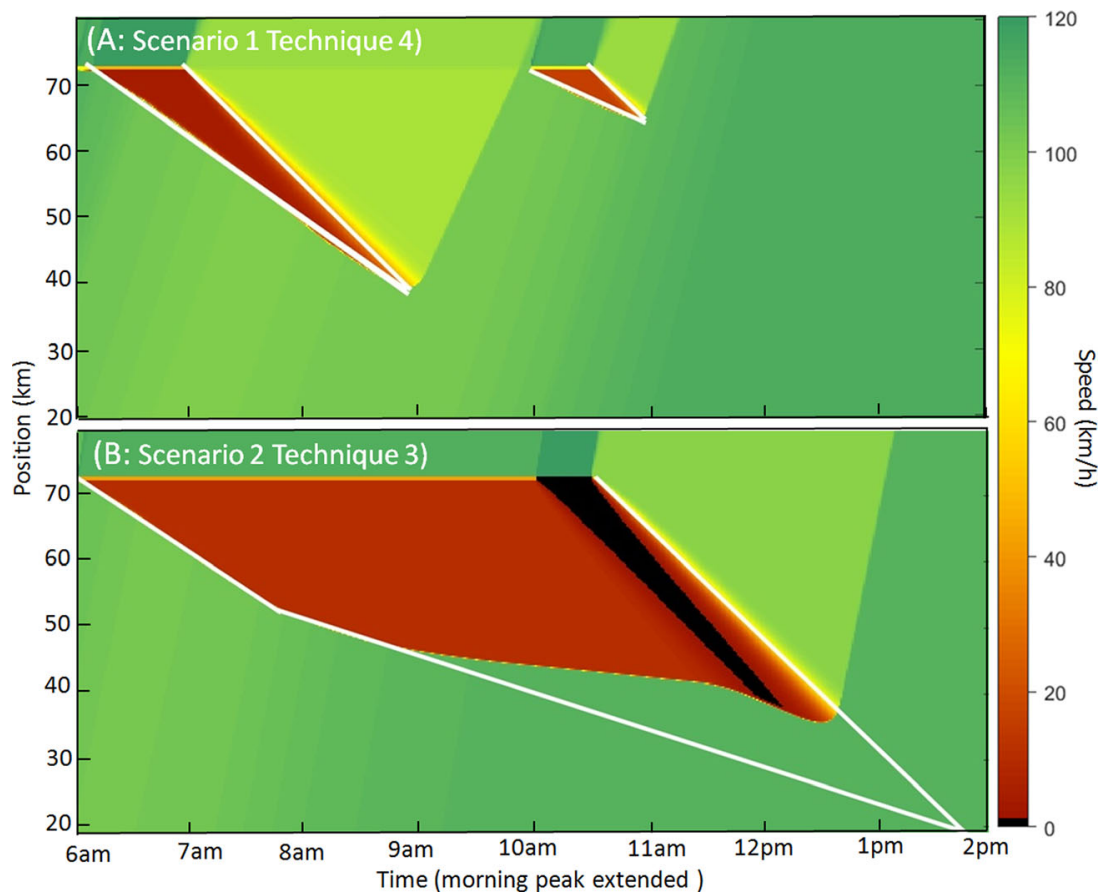


Table 10 Comparing results simulated by CTM-v and queue model aggregated for all sub-cases of Scenario and Technique with one level of demand for each, comparing only congested locations upstream of the incident (the largest differences are highlighted)

\begin{tabular}{|c|c|c|c|c|c|c|c|c|c|}
\hline \multirow[b]{2}{*}{ Scenario } & \multirow[b]{2}{*}{ TIM Technique } & \multirow[b]{2}{*}{$\begin{array}{l}\text { Demand } \\
\text { peak }\end{array}$} & \multicolumn{4}{|c|}{ CTM simulation } & \multicolumn{3}{|c|}{ Queue model } \\
\hline & & & $\begin{array}{l}\text { Total } \\
\text { delay } \\
\text { [veh-h] }\end{array}$ & $\begin{array}{l}\text { Max } \\
\text { extent } \\
{[\mathrm{km}]}\end{array}$ & queue & $\begin{array}{l}\text { Total } \\
\text { duration } \\
{[\mathrm{h}]}\end{array}$ & $\begin{array}{l}\text { Total } \\
\text { delay } \\
\text { [veh-h] }\end{array}$ & $\begin{array}{l}\text { Max queue } \\
\text { extent } \\
{[\mathrm{km}]}\end{array}$ & $\begin{array}{l}\text { Total } \\
\text { duration } \\
{[\mathrm{h}]}\end{array}$ \\
\hline 1 & 1.1 (close all lanes) & High long & 16612 & 58 & & 5.0 & 17265 & 67 & 5.3 \\
\hline 1 & 1.2 (incident screen) & High long & 23878 & 63 & & 5.6 & 23941 & 73 & 5.9 \\
\hline 1 & 1.3 (close some lanes) & High long & 11018 & 50 & & 4.5 & 11413 & 55 & 4.6 \\
\hline 1 & 1.4 (tow in off-peak) & High long & 4101 & 33 & & 4.9 & 4066 & 33 & 5.0 \\
\hline 2 & 2.1 (close all lanes) & High & 10109 & 42 & & 3.9 & 10292 & 51 & 4.3 \\
\hline 2 & 2.2 (contraflow) & High & 6409 & 34 & & 3.4 & 7266 & 42 & 3.8 \\
\hline 2 & 2.3 (VMS+speed limit) & High & 18908 & 37 & & 6.6 & 23529 & 60 & 7.7 \\
\hline 3 & 3.1 (close extra lane) & High long & 2469 & 27 & & 2.7 & 2603 & 27 & 2.5 \\
\hline 3 & 3.2 (repair on site) & High long & 1590 & 16 & & 4.9 & 1412 & 14 & 4.9 \\
\hline 3 & 3.3 (tow in off-peak) & High long & 29301 & 45 & & 7.2 & 28014 & 55 & 7.6 \\
\hline 4 & 4.1 (close all lanes) & Constant & 3740 & 20 & & 2.6 & 3764 & 20 & 2.6 \\
\hline 4 & 4.2 (contraflow) & Constant & 1974 & 11 & & 2.1 & 1908 & 11 & 2.1 \\
\hline 4 & 4.3 (close blocked lane) & Constant & 999 & 7 & & 2.0 & 1024 & 7 & 2.0 \\
\hline
\end{tabular}

The macroscopic queue model generally overestimates queue extent, duration and delay, the worst cases being those highlighted in Table 10. However, the absolute errors in delay are under $20 \%$ except for the case of Scenario 2 (Weather event) with Technique 2.3 (VMS + Speed limit), as shown in Fig. 9b, and errors in duration are under 10\%. The physical extent of the queue appears to be the most difficult quantity to estimate. As discussed earlier, a weather event, producing unsafe road conditions requiring a speed limit, appears to be the most difficult situation to model consistently, bearing in mind the simplifying assumptions involved in modelling the effect of a speed limit.

\section{Conclusions and future research needs}

The purpose of PRIMA as a whole is to aid decisions on whether and how to invest in Pro-Active TIM techniques. Full benefit-cost analysis must take into account the cost of any investment and, if applicable to the business case, the potential saving of the cost of incidents to the taxpayer, both of which involve uncertainty due to differences in local or national conditions, labour and deployment costs, accident rates, ascription of values of time, rapid escalation of accident costs with severity, and the inherent unpredictability of incidents. Although outside the remit of the PRIMA project, conflict prediction and incident prevention are likely to play a part in pro-active TIM. An ability to predict traffic conditions and risk of incidents $30 \mathrm{~min}$ ahead would also be advantageous for traffic managers. Validated versions of the traffic models presented here for off-line TIM analysis, could with some adjustments be used as an on-line tool to assist traffic managers and
TMCs to make quick estimations of the best TIM actions to apply. The incident modelling method using the CTM-v can be implemented directly in the Mobile Millennium travel time prediction platform.

Modelling methods A critical issue for present purposes is how important are the differences between the CTM-v simulation and the macroscopic queue model for reaching conclusions about the most effective Pro-Active TIM techniques and for estimating the benefit-cost ratios of interventions, as discussed in Nitsche et al. [1], and project reports Taylor et al. [2,3]. It is clear from the results in Table 10 that the modelling errors or uncertainties of the order 10-20\% affect neither general magnitudes nor ordering of results for the Scenario/Technique combinations, which vary by nearly a factor of 30 , or one and a half orders of magnitude, in delay. Bearing in mind that site, traffic and weather conditions can also vary considerably, that no two incidents are identical, and that the precise course of an incident is difficult to predict, it is unlikely that higher precision would lead to a qualitatively different outcome. It is concluded that the macroscopic queue model gives adequate resolution for the purposes of a broad comparative assessment.

Incident data collection During the PRIMA project, some historical and one large recent incident data sets were obtained and analysed as reported by Taylor [21]. However, the recorded data were found to be incomplete and inconsistent between data sets, making it difficult to estimate the length and impact of different incident phases. In some cases narrative descriptions were used making structured 
Table 11 Sample incident datasets with breakdown of attributes recorded and recommended

\begin{tabular}{|c|c|c|c|c|c|c|c|}
\hline Data set & 1 & 2 & 3 & 4 & 5 & 6 & Coverage (1-5) \\
\hline Number of months & 7 & 12 & 10 & 2 & 15 & 29 & 27 \\
\hline Number of incidents & 1018 & 942 & 5277 & 128 & 8322 & 103,359 & 15,687 \\
\hline Of which accidents & 621 & 238 & 1059 & 112 & 1355 & 21,374 & 3385 \\
\hline Attributes desired & \multicolumn{6}{|c|}{ Attributes recorded } & Sets $1-5$ only \\
\hline Road identifier & $\checkmark$ & $\checkmark$ & $\checkmark$ & $\checkmark$ & $\checkmark$ & $\checkmark$ & $100 \%$ \\
\hline Date & $\checkmark$ & $\checkmark$ & $\checkmark$ & $\checkmark$ & $\checkmark$ & $\checkmark$ & $100 \%$ \\
\hline Start time & $\checkmark$ & $\checkmark$ & $\checkmark$ & $\checkmark$ & $\checkmark$ & $\checkmark$ & $100 \%$ \\
\hline Response time & $\otimes$ & $\otimes$ & $\checkmark$ & $凶$ & $\otimes$ & $凶$ & $20 \%$ \\
\hline Cause & $\checkmark$ & $\checkmark$ & $\checkmark$ & $\checkmark$ & $\checkmark$ & $\checkmark$ & $100 \%$ \\
\hline Duration & $\checkmark$ & $\checkmark$ & $\checkmark$ & $\checkmark$ & $\checkmark$ & $\checkmark$ & $100 \%$ \\
\hline Severity & $\otimes$ & $\checkmark$ & $\checkmark$ & $\checkmark$ & $\checkmark$ & 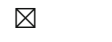 & $60 \%$ \\
\hline Number of lanes available & $\otimes$ & $\checkmark$ & $\otimes$ & $凶$ & $\otimes$ & $\otimes$ & $20 \%$ \\
\hline Number of lanes closed & $\checkmark$ & $\otimes$ & $凶$ & $\checkmark$ & $\otimes$ & $\otimes$ & $40 \%$ \\
\hline Heavy vehicle involved & $\checkmark$ & $\checkmark$ & $\checkmark$ & $\checkmark$ & $\otimes$ & $\otimes$ & $80 \%$ \\
\hline Number of vehicles involved & $\otimes$ & $\checkmark$ & $\otimes$ & $\checkmark$ & $\otimes$ & $\otimes$ & $40 \%$ \\
\hline Number of persons/injuries & $\otimes$ & $\checkmark$ & $\otimes$ & $\checkmark$ & $\otimes$ & $\otimes$ & $40 \%$ \\
\hline Delay/Effect on traffic & $\otimes$ & $\checkmark$ & $\otimes$ & $\checkmark$ & $\otimes$ & $\checkmark$ & $40 \%$ \\
\hline Numerical delay estimate & $\otimes$ & $\otimes$ & $\otimes$ & $凶$ & 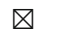 & $\checkmark$ & $0 \%$ \\
\hline Directions affected & $\checkmark$ & $\checkmark$ & $\otimes$ & $\checkmark$ & 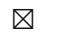 & $\otimes$ & $60 \%$ \\
\hline Information about diversions & $\otimes$ & $\checkmark$ & $\otimes$ & $\checkmark$ & $\otimes$ & $\otimes$ & $40 \%$ \\
\hline Keywords or Text & $\checkmark$ & $\checkmark$ & $\checkmark$ & $\checkmark$ & $\checkmark$ & $\checkmark$ & $100 \%$ \\
\hline
\end{tabular}

analysis difficult or unreliable. Even where data were assessed as recorded, this could involve a degree of inference. For example, in all the data sets analysed either the number of lanes closed or the number of lanes open was given, but never both, so to get a full picture it was necessary to obtain from elsewhere, or assume, the number of lanes normally available at the incident site, without knowing whether the situation was affected by slip lanes or temporary use of the hard shoulder. Severity could also be difficult to establish, and whether a large goods vehicle (LGV) was involved was not always recorded. To enable more complete and reliable analysis, TMCs should ideally record all details of the TIM actions they apply, including how many lanes are available and closed and at what exact times, plus the traffic state at these times. An anonymised version of the Table in the reference is included below, in the hope of giving this issue wider airing than might otherwise happen (Table 11).

Future research In order for the traffic models to be fully dependable, further calibration and validation are needed. First, there should be empirical investigation of how incidents and TIM actions affect not only capacity but also the speed-flow-density relationships. Second, the modelestimated travel delays, queue lengths, durations, etc. should be validated using data from real world incidents. This should be conducted using data sets other than the ones used to calibrate the speed-flow-density relationships. Third, solution schemes of the LWR model other than the CTM-v, as event-based continuous-in-time solutions, should be investigated as an alternative to the macroscopic queue model. The LWR model can be applied without iteration to the events where waves of disturbance in a queue related to changes in capacity interact with changes in arrival flows. This is more intricate but could resolve the question concerning head wave speeds in the macroscopic queue model.

Acknowledgements The PRIMA project was funded by the Conference of European Directors of Roads (CEDR) which represents the heads of National Road Administrations in Europe. The Netherlands Organisation for Applied Scientific Research (TNO) also participated in PRIMA in relation to new technology and ergonomics. Comments by Dr. Alan Stevens, Transportation Chief Scientist at the UK Transport Research Laboratory (TRL), and four anonymous reviewers, are gratefully acknowledged. TRL's participation in previous CEDR projects was supported by Highways England.

Publisher's Note Springer Nature remains neutral with regard to jurisdictional claims in published maps and institutional affiliations.

Open Access This article is distributed under the terms of the Creative Commons Attribution 4.0 International License (http:// creativecommons.org/licenses/by/4.0/), which permits unrestricted use, distribution, and reproduction in any medium, provided you give appropriate credit to the original author(s) and the source, provide a link to the Creative Commons license, and indicate if changes were made. 


\section{References}

1. Nitsche P, Olstam J, Taylor N, Reinthaler M, Ponweiser W, Bernhardsson V, Mocanu I, Uittenbogaard J, van Damm E (2016) Pro-active management of traffic incidents using novel technologies. Proc. 6th Transport Research Arena (TRA) conference, Warsaw, 18-21 April 2016

2. Taylor NB, Nitsche P, Van Rooij L, Bernhardsson V, Mocanu I, Olstam J (2015a) Report on best practice, needs and derived incident scenarios. PRIMA Deliverable 2.2. CEDR, Paris. http://urn.kb. se/resolve?urn=urn:nbn:se:vti:diva-8014

3. Taylor NB, Olstam J, Bernhardsson V (2015b) Description and results of cost-benefit and risk assessment. PRIMA Deliverable 3.2. CEDR, Paris. http://urn.kb.se/resolve?urn=urn:nbn:se:vti: diva-8014

4. CEDR (2009) Traffic incident management. Final report of Task 5. CEDR, Paris. http://www.cedr.eu/download/Publications/2009/e Traffic_Incident_Management.pdf

5. CEDR (2012) Best practice in European traffic incident management. Final report of Task 13. CEDR, Paris. http://www. cedr.eu/download/Publications/2012/e Incident Management.pdf

6. CEDR (2013) Traffic management to reduce congestion. Final report of Task 12. CEDR, Paris. http://www.cedr.eu/download/ Publications/2013/T12_Traffic_management.pdf

7. Highways England (2009) Traffic incident management guidance framework. January 2009. http://webarchive.nationalarchives.gov. uk/20110606115148/http://www.highways.gov.uk/business/ 20055.aspx

8. VCNL (2010) The roles of the emergency services in incident management in the Netherlands. Verkeerscentrum Nederland. http:// www.incidentmanagement.nl//index.php?option=com content\&task=view\&id=141\&Itemid $=135$

9. Taylor NB (2010) Defining best practice in European traffic incident management. Proc. 3rd Transport Research Arena (TRA) conference, Brussels, 7-10 June 2010
10. Taylor NB, Notley S, Bourne N, Skrobanski G (2008) Evidence for speed-flow relationships. Proc. European transport conference, Leeuwenhorst, 6-8 October 2008, Association for European Transport

11. Duncan NC (1979) A further look at speed/flow/concentration. Traffic Eng Control 20(10):482-483

12. Banks JH (1989) Freeway speed-flow-concentration relationships: more evidence and interpretations. Transportation research record 1225. Transportation Research Board, Washington, DC

13. HCM (2010) Highway capacity manual. Volume 1: concepts. Transportation Research Board, Washington DC. This has recently been updated to a Sixth Edition (2016), http://www.trb.org/Main/ Blurbs/175169.aspx

14. Daganzo CF (1994) The cell transmission model: a dynamic representation of highway traffic consistent with the hydrodynamic theory. Transp Res B 28:269-287

15. Bayen A, Butler J, Patire A (2011) Mobile millennium final report. UC Berkeley, Berkeley. See also http://www. mobilemillenniumstockholm.se/

16. Lighthill MJ, Whitham GB (1955) On kinematic waves II: a theory of traffic flow on long, crowded roads. Proc R Soc London, Ser A 229:317-345

17. Richards PI (1956) Shock waves on the highway. Oper Res 4:42-51

18. Godunov S (1959) A difference method for the numerical calculation of discontinuous solutions of hydrodynamic equations. Math. Sbornik, 47, 271-306, translated US Joint Publ. Res. Service, JPRS 7226, 1969

19. Work DB, Blandin S, Tossavainen OP, Piccoli B, Bayen AM (2010) A traffic model for velocity data assimilation. Appl Math Res Express 2010:1-35

20. Taylor NB (2009) The management and impact of abnormal loads. TRL Insight Report INS004. Transport Research Laboratory, Crowthorne House

21. Taylor NB (2015) Characteristics and durations of road traffic incidents. PRIMA Deliverable 3.2 (Supplementary). CEDR, Paris 